\title{
Human brown adipose tissue
}

Citation for published version (APA):

Moonen, M. P. B., Nascimento, E. B. M., \& van Marken Lichtenbelt, W. D. (2019). Human brown adipose tissue: Underestimated target in metabolic disease? Biochimica et Biophysica Acta-Molecular and Cell Biology of Lipids, 1864(1), 104-112. https://doi.org/10.1016/j.bbalip.2018.05.012

Document status and date:

Published: 01/01/2019

DOI:

10.1016/j.bbalip.2018.05.012

Document Version:

Publisher's PDF, also known as Version of record

Document license:
Taverne

Please check the document version of this publication:

- A submitted manuscript is the version of the article upon submission and before peer-review. There can be important differences between the submitted version and the official published version of record.

People interested in the research are advised to contact the author for the final version of the publication, or visit the DOI to the publisher's website.

- The final author version and the galley proof are versions of the publication after peer review.

- The final published version features the final layout of the paper including the volume, issue and page numbers.

Link to publication

\footnotetext{
General rights rights.

- You may freely distribute the URL identifying the publication in the public portal. please follow below link for the End User Agreement:

www.umlib.nl/taverne-license

Take down policy

If you believe that this document breaches copyright please contact us at:

repository@maastrichtuniversity.nl

providing details and we will investigate your claim.
}

Copyright and moral rights for the publications made accessible in the public portal are retained by the authors and/or other copyright owners and it is a condition of accessing publications that users recognise and abide by the legal requirements associated with these

- Users may download and print one copy of any publication from the public portal for the purpose of private study or research.

- You may not further distribute the material or use it for any profit-making activity or commercial gain

If the publication is distributed under the terms of Article $25 \mathrm{fa}$ of the Dutch Copyright Act, indicated by the "Taverne" license above, 
Review

\title{
Human brown adipose tissue: Underestimated target in metabolic disease? ${ }^{\text {hr }}$
}

\author{
Michiel P.B. Moonen, Emmani B.M. Nascimento, Wouter D. van Marken Lichtenbelt*,1,2 \\ NUTRIM School of Nutrition and Translational Research in Metabolism, Departments of Nutrition and Human Movement Sciences, Maastricht University, Maastricht, the \\ Netherlands
}

\section{A R T I C L E I N F O}

\section{Keywords:}

Brown adipose tissue

Energy metabolism

\begin{abstract}
A B S T R A C T
Active brown adipose tissue (BAT) has, since it rediscovery in adult humans in 2009, received much attention for its ability to increase energy expenditure when activated. By means of mitochondrial uncoupling activity BAT's main function is to produce heat instead of storing energy such as in white adipose tissue (WAT). Therefore, BAT is considered a new potential target to treat obesity and the metabolic syndrome. However, the contribution of this thermogenic tissue is still a matter of debate among researchers.

The aim of this review is to give an overview of the differences between classical brown adipocytes and inducible beige adipocytes in humans, and the potential activators of BAT in humans. Furthermore newly described genetic markers for identification of these two types of brown adipocytes are examined. Finally, the potential of the current measurement techniques, and the contribution of BAT activity to whole body energy expenditure are discussed.
\end{abstract}

\section{Introduction}

In modern society, energy intake often exceeds energy expenditure. This in turn leads to obesity, in which excess energy is stored in white adipose tissue (WAT). Under a microscope, WAT can be recognized by the presence of a single large lipid droplet and few mitochondria. In contrast brown adipose tissue (BAT) is characterized by large amounts of mitochondria and a relatively small capacity of fat storage, and most importantly is responsible for non-shivering thermogenesis [1]. At least in animals BAT plays a dominant role in maintaining body temperature in the cold. The first description of BAT was by Konrad Gessner in 1551, who described it as 'as nor flesh nor fat'. In 1985, Himms-Hagen described BAT as a tissue containing multilocular adipocytes with multiple lipid-containing droplets and many mitochondria [2]. The presence of uncoupling protein 1 (UCP1 aka thermogenin) in the mitochondria of BAT enables heat production. UCP1 uncouples the proton gradient of the electron transport chain that would normally be used to generate ATP, thus resulting in heat production [1].

In newborns of precocial species such as deer and lamb BAT is predominantly found in the perirenal fat deposit, while in rodents, and human newborns, it is mainly found in the interscapular area, as well as in cervical, para-aortal and subcostal area [2]. In early studies by Huttunen et al. in 1981 and by Heaton in 1972 brown adipocytes were seen in multiple adipose tissue depots in human subjects, in several age categories $[3,4]$. Nevertheless, the assumption was that in humans BAT dissipates with age and interest in BAT was diminished. However in 2007, Nedergaard et al. reviewed nuclear imaging studies in humans that showed that the uptake of ${ }^{18} \mathrm{~F}^{-}$FDG (glucose) in the neck and shoulder region, was by brown adipose tissue [5]. Then in 2009, three independent research groups identified functional cold activated BAT in adult humans [6-8] igniting the discussion of its importance in human physiology and metabolism. Since then studies on BAT increased dramatically, although the amount of well-controlled intervention studies in humans is relatively scarce compared to number of animal studies, cell studies and retrospective studies. The importance and contribution of human BAT in whole body metabolism is still not understood despite this strong revival of studies on BAT $[9,10]$. In this review we will first discuss different types of thermogenic and UCP1-positive adipocytes. Next, we will discuss different ways to activate and measure BAT activity. Finally, we will examine the potential role of human BAT activity in relation to whole body metabolism and energy expenditure to prevent and/or treat obesity and the metabolic syndrome.

\footnotetext{
This article is part of a special issue entitled Brown and Beige fat: From molecules to physiology guest editor: Paul Cohen.

* Corresponding author at: NUTRIM School of Nutrition and Translational Research in Metabolism, Departments of Nutrition and Human Movement Sciences, the Netherlands.

E-mail address: markenlichtenbelt@maastrichtuniversity.nl (W.D. van Marken Lichtenbelt).

${ }^{1}$ Visiting address: Universiteitssingel 50, 6229 ER, Maastricht, The Netherlands.

${ }^{2}$ Post-address: P.O. Box 616, 6200 MD Maastricht, The Netherlands.
} 


\section{Defining the brown adipocyte}

\subsection{Brown adipocytes vs. beige/brite adipocytes}

In order to understand the role of BAT at whole body level, we first need to examine what defines brown adipocytes. Presence and activation of uncoupling protein 1 (UCP1) in BAT is crucial for its function to produce heat. UCP1 is located in the inner membrane of mitochondria where it influences the proton gradient in oxidative phosphorylation. Normally oxidative phosphorylation generates ATP via the proton gradient that is present between the mitochondrial matrix and the mitochondrial intermembrane space. However, when activated, UCP1 uncouples the proton gradient from ATP-synthase thereby generating heat instead of ATP. Cold is the most effective way to activate BAT. Cold exposure stimulates thermoreceptors in the skin, which in turn activate neurons in the ventromedial nucleus of the hypothalamus, leading to the release of norepinephrine [1,11]. The importance of the sympathetic nervous system is shown in studies with pharmacological blockade of adrenergic receptors, or lesions in the ventromedial nucleus in animals [12,13]. In one such study, injections with glutamate into the ventromedial nucleus in mice induced a dose-dependent stimulation of interscapular BAT [12], while another study showed that $\beta$-blockade via propranolol results in reduced BAT activity [13].

Norepinephrine binds the $\beta 3$ adrenergic receptor on the brown adipocyte thereby activating the intracellular signalling cascade. Via second messenger cyclic AMP, activated protein kinase A (PKA) binds cAMP responsive binding element (CREB) stimulating gene transcription of UCP1. Secondly, PKA can directly stimulate lipolysis by activating hormone sensitive lipase (HSL) leading to the release of fatty acids from the intracellular lipid droplet. These intracellular released fatty acids also stimulate UCP1 [11]. Besides the essential sympathetic activity, other factors influence BAT activity as well. CREB stimulates transcription of iodothyronine deiodenase 2 (DIO2), which stimulates intracellular conversion of inactive thyroid hormone $\mathrm{T} 4$ to active thyroid hormone T3 [11]. Optimal BAT thermogenesis depends on intracellular levels of T3 $[14,15]$, which explains the association between hypothyroidism and lower body temperature and the feeling of cold [16].

UCP1 is a requisite for uncoupling in adipocytes, however UCP1 expression is not always similar in thermogenic adipocytes found in different adipose tissue depots. In rodents, the presence and activity of BAT is a well-known and studied fact [17]. In these animals, the interscapular depot is most recognized for the presence of brown adipocytes [2]. These brown adipocytes are usually referred to as constitutive or classical brown adipocytes (cBAT). These cBAT cells are UCP1 positive, even without cold stimulation. Furthermore, classical brown adipocytes are myogenic factor 5 (myf5) positive indicating a similar lineage as skeletal muscle [18]. Peroxisome proliferator activated receptor gamma coactivator 1 alpha (PGC1a) is known as an important regulator of mitochondrial biogenesis and plays a crucial role in adipogenesis of thermogenic adipocytes. Next to that PGC1a is able to activate the UCP1 gene in BAT [19]. PGC1a target PR domain zinc finger protein 16 (PRDM16) is a key element in differentiation of brown adipocytes in mice and humans. Indeed, knock down of PRDM16 in precursor cells for brown adipocytes, redirected differentiation in the direction of muscle cells [20]. In addition, in PRDM16 knockout mice, the BAT depots showed clear signs of whitening [21]. Upon cold exposure, the white adipose tissue depots, showed no sign of compensatory browning. The adipose cells in knockout mice contained very few mitochondria, with less mitochondrial organisation then in wild type mice [21]. During cold exposure the knockout mice had a larger drop in core temperature then wild type mice, and total body energy consumption upon NE exposure was clearly depressed in the knockout mice. All in all these results show the importance of PRDM16 in the regulation of $\mathrm{BAT}$ in mice [21].

Cold exposure in rodents can transform the adipocytes in WAT. The discovery of recruitable adipocytes was already reported in 1984 in rodent WAT following cold [22]. These changes include, among others, increased mitochondrial biosynthesis and expression of UCP1, enabling a shift towards a brown adipocyte phenotype [23]. These recruitable adipocytes appeared to be from a myf5 negative lineage and are referred to as beige or brite (=brown in white) adipocytes [20,23]. Histology clearly shows presence of these recruitable adipocytes in WAT following prolonged cold exposure [24]. Though originally from different lineages, classical brown adipocytes and recruitable adipocytes have similar cellular structure. Both possess paucilocular fat droplets and multiple mitochondria [24,25]. Both also show strong activation upon cold exposure [24] as both types use UCP1 to uncouple ATP production to produce heat.

In mice, the development of these recruitable brown adipocytes is a genetically controlled process because certain mouse strains display major increases in UCP1 expression in WAT following cold stimulation while others do not [26]. Furthermore in a knockout model, mice without cBAT compensate this loss by developing recruitable BAT [17]. There are also strong indications that britening and whitening occurs through a direct interconversion of a white adipocyte into a brown adipocyte phenotype, a process referred to as transdifferentiation, in which the earlier mentioned PDRM16 plays an important role [21,27]. The main difference between cBAT and recruitable adipocytes is the presence of UCP1. In cBAT, UCP1 is always present, while in recruitable adipocytes UCP1 is upregulated following appropriate stimulation like cold exposure.

In adult humans, biopsy material does not always resemble cBAT as seen in rodents. Biopsies of human BAT are UCP1 positive in adults and infants [6-8,28], however it has been suggested that adipocytes in adult human BAT are more of a recruitable nature compared to classical brown adipocytes [24,29]. Furthermore it is not known whether myf5 positive UCP1 positive adipocytes are present in humans. The suggestion that murine recruitable adipocytes are derived from a smoothmuscle like origin [30] might also hold true for human brown adipocytes.

While cBAT in rodents persists with ageing [2], BAT in humans seems to dissipate in the elderly [31]. BAT activity is also lower in obese subjects, with an improvement after weight loss [32]. However recruiting BAT is a proven concept, both in obese and older human subjects [33-35]. These studies lead to the conclusion that recruiting BAT is a distinct possibility to influence energy metabolism in humans. We will discuss measuring BAT activity in humans below in Section 3.

\subsection{Markers for $B A T$}

Although the composition and origin of BAT in humans is still under debate, it is evident that the adipocytes in human BAT are UCP1 positive and that these cells have the potential of norepinephrine and cold-stimulated thermogenesis [36]. It should be noted that BAT in mouse and man cannot simply be compared. Many publications are dedicated to identify molecular markers in order to distinguish thermogenic adipocytes [24,37-40]. Although UCP1 is the right marker of choice when examining brown and recruited adipocytes, it might not be the most practical marker, because it is located inside the mitochondria. Therefore the scientific community has been looking for other markers aimed to identify UCP1 positive adipocytes that are preferentially expressed at the cell surface, in order to easily extract these cells via cell sorting experiments that could aid to further elucidate the origin of recruitable adipocytes in humans. Also in general, the discovery of novel markers of UCP1 positive adipocytes could help in drug development to enhance thermogenesis. It is not our goal to review all markers associated with BAT identity (for review see [41]). Here we present a selection of the most recently discovered molecular markers with high potential aimed to identify UCP1 positive adipocytes in humans, as shown in Fig. 1. The discussed markers can either be targeted by pharmacological means or they provide novel insights into BAT 


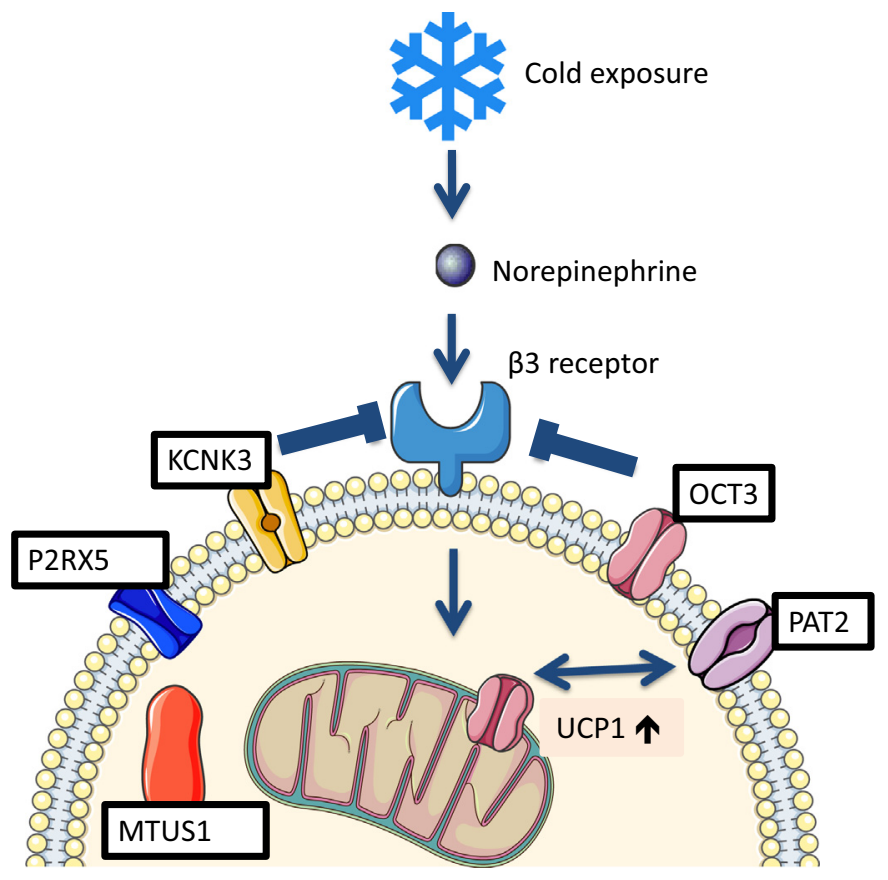

Fig. 1. Overview of discussed recently identified cellular markers for human brown adipocytes. In the central pathway, cold exposure acting through norepinephrine on the $\beta 3$ receptor is shown, resulting in increased UCP1 expression. UCP1 (uncoupling protein 1); OCT3 (organic cation transporter 3); PAT2 (proton/amino acid transporter 2); P2RX5 (purinergic receptor P2X, ligandgated ion channel 5); MTUS1 (mitochondrial tumor suppressor 1); KCNK3 (pH sensitive potassium channel, subfamily $\mathrm{K}$, member 3 ).

origin and physiology.

As mentioned earlier BAT is dependent on norepinephrine release from the sympathetic neuron. Following norepinephrine release, it binds $\beta 3$ adrenergic receptor thereby activating BAT. The uptake of norepinephrine in adipocytes is inhibited by cell membrane transporter organic cation transporter 3 (OCT3). This transporter is able to shuttle various hormones across the cell membrane. Although ubiquitously expressed [42], higher expression can be detected in deep neck adipose tissue compared to human subcutaneous WAT [43]. OCT3 function can be inhibited by corticosterone [43]. This opens pathways for future venues to develop pharmacological intervention directed to OCT3 that could stimulate human BAT activity.

The PAT2 gene encodes a $\mathrm{pH}$ dependent proton/amino acid transporter that is selective for small chain amino acids [44]. The transcript for this gene was detected primarily in skeletal muscle and kidney [45]. When it comes to adipose tissue, PAT2 expression is specific for human BAT compared to subcutaneous WAT [46], however PAT2 was not detected in brown-like/recruitable adipocytes from children in WAT [47] although these samples were UCP1 positive. With an eye towards the future, PAT2 is a valuable marker to detect adipocytes that express UCP1. Because PAT2 is a cell surface expressed protein, this gives openings to isolate cells via cell sorting.

Purinergic receptor P2X, ligand-gated ion channel 5 (P2RX5) belongs to a family of extracellular ATP-gated ion channels. The ion channel localizes to the cell membrane and its expression is high in immune system and brain [48]. P2RX5 is sensitive to changes in extracellular concentrations of calcium [49]. In adipose tissue, P2RX5 shows specificity towards human BAT over subcutaneous WAT [46]. In mice, P2RX5 is expressed in murine brown preadipocytes and its expression is further increased during adipocyte differentiation. Furthermore, expression of P2RX5 was increased following cold stimulation in mice in both BAT and subcutaneous WAT [46] similar to the response as UCP1.
Mitochondrial tumor suppressor 1 (MTUS1 also known as ATIP) is a mitochondrial protein that controls cellular proliferation [50]. MTUS1 expression is higher in human BAT compared to WAT. MTUS1 expression can be regulated via cold, because human BAT biopsies after prolonged cold exposure showed an increase in MTUS1 [51]. Knockdown of MTUS1 in human cultured brown adipocytes resulted in reduced UCP1 expression and decreased mitochondrial uncoupling suggesting a role in BAT thermogenesis [51]. Interestingly in mice, overexpression of MTUS1 resulted in reduced inflammation, less recruitment of macrophages and increased insulin sensitivity in WAT [52]. These findings in WAT might suggest that BAT might handle an inflammatory insult better resulting in normal metabolism.

KCNK3 (also known as TASK) encodes a pH sensitive potassium channel, subfamily K, member 3 [53]. Expression of KCNK3 is specific to human BAT compared to human WAT [51,54], and KCNK3 expression shows a negative correlation to age or BMI in human BAT [55]. The amount of KCNK3 is correlates with PRDM16 [51,56]. KCNK3 negatively affects second messenger signalling of the beta-adrenergic receptor via cAMP [56]. $\mathrm{KNCK}^{-/-}$mice are obese and their brown adipocytes show resistance at the level of activation of the beta-adrenergic receptor [56]. Furthermore the explanation for this phenotype was through enhanced mineralocorticoid receptor signalling, which could be targeted by inhibitor eplerenone [56]. KCNK3 is an interesting marker to identify BAT, which in the future could result in novel methods to stimulate BAT in humans.

Adenosine, is product of ATP breakdown, however it can also act as a signalling molecule via interaction with adenosine and purinergic receptors. Adenosine stimulates in vitro BAT activity and this stimulatory effect is further enhanced by adrenergic stimulation. More specific, an agonist for the $\mathrm{A}_{2 \mathrm{~A}}$ receptor markedly increased in vitro BAT activity. In murine experiments stimulation of BAT with norepinephrine results in release of adenosine further linking adenosine to BAT activity [57]. Novel ligands have been designed to target the $A_{2 A}$ receptor (for review see [58]), however it remains to be seen how these compounds can affect human BAT activity.

\subsection{Summary/take home message}

Contrary to many rodent species, adipocytes detected in adult human BAT biopsies are mostly of a recruitable nature (beige or brite adipocytes) [24]. Characterisation of these recruitable brown adipocytes can be useful to better understand the origin of these adipocytes and to ultimately devise new strategies to stimulate thermogenesis in humans. Earlier attempts to characterize these recruitable BAT cells were built upon the use of genetic and intracellular markers, which often gave inconclusive results. Several new markers with high potential have been discovered in the recent past, especially to detect these BAT cells using cell membrane specific markers. These new markers focus on activation of BAT cells using different interventions.

\section{Brown adipose tissue activation and detection in humans}

\subsection{BAT activity stimulation besides cold exposure}

Besides cold exposure, pharmacological stimulants have also been tested in humans. A non-selective systemic beta-adrenergic stimulation, by isoprenaline [59] and ephedrine [60] did not show significant activation in BAT glucose uptake and resulted in negative cardiovascular side effects [59]. More promising results are found in the use of a selective B3 stimulant, mirabregon. This showed an elevated uptake in BAT upon stimulation [61] comparable to cold activation. However the needed dosage and potential side effects are still matter of debate. Systemic administration of pharmacological stimulants is not selective for BAT only, as it also affects other tissues, such as white adipose tissue.

The suspected relationship between BAT activity in humans and 
diet-induced thermogenesis (DIT) has also been an interesting topic. As reviewed by Kozak [62], the theory that excessive energy with food intake is expended as heat through BAT activation has not been proven. Vosselman et al. [63] compared BAT activity after meal consumption with cold exposure. They found that the amount of BAT activity did increase after large meal consumption, however there was no relationship with DIT.

BAT may still be stimulated through certain dietary components such as components in green tea (cathechin-polyphenols and caffeine), peppers (capsinoids) and menthol $[64,65]$. Green tea extract contains cathechin-polyphenols, which are able to inhibit catechol-O-methyltransferase, the enzyme responsible for the breakdown of sympathically released norepinephrine. The caffeine, present in green tea extract, is believed to inhibit phosphodiesterase, which in turn breaks down the cAMP second messenger system. Furthermore, caffeine also acts as antagonist on adenosine receptors (see above). Green tea extract could thus be used to potentiate the adrenergic and/or via adenosine pathways and thus lead to more BAT activation [65].

The pungent capsaicinoids, found in peppers are able to stimulate BAT activity via the transient receptor potential channels (TRPV) [64]. Stimulation of TRPV channels in the brain would lead to more sympathic activity and in turn to increased BAT activity. However the strong pungency, may lead to reduced intake or gastro-intestinal side effects [66]. The non-pungent forms, known as capsinoids, have been studied in their potential to stimulate BAT [67]. However, this study only showed a higher increase in energy expenditure upon cold exposure in BAT positive subjects compared to BAT negative subjects using capsinoids.

Another recently discovered potential stimulant in humans is sildenafil. Sildenafil is a well-known phosphodiesterase type 5 (PDE5) inhibitor, commonly used to treat erectile dysfunction in men. By inhibiting PDE5, it can elevate levels of cGMP via guanylyl cyclase, which in turn can further stimulate lipolysis in BAT cells. Sildenafil was shown to induce browning in human WAT [68], and could thus be an interesting target for study in humans.

As seen in earlier studies, the direct stimulation of soluble guanylyl cyclase has already shown to increase whole-body energy expenditure and lipid uptake in BAT in mice, as well as inducing browning of murine white adipocytes $[69,70]$. This makes increasing cGMP an interesting potential target for BAT stimulation.

\subsection{Measurement of BAT activity in humans}

In order to determine the role and the contribution of BAT to whole body metabolism in adult humans, quantitative measurements of BAT activity are needed. The rediscovery of the presence of active BAT in humans was accomplished by positron emission tomography/computed tomography (PET/CT) scan with a radioactive labelled glucose tracer, 18-Fluor-Deoxy-Glucose $\left({ }^{18} \mathrm{~F}^{-} \mathrm{FDG}\right)$ [6-8]. Ever since, the ${ }^{18} \mathrm{~F}^{-}$FDG$\mathrm{PET} / \mathrm{CT}$ technique has been the most used test for detecting the presence of BAT in humans. Alternatively, some studies use other substrate tracers such as 18 -Fluor 6-thia-heptadecanoidic acid $\left({ }^{18}\right.$ F-FTHA) as a marker for fatty acid uptake.

Besides substrate uptake, several other aspects of BAT activity can be measured such as oxidative metabolism, local blood perfusion and sympathic innervation. In the following we will discuss the usefulness of some of these techniques to quantify the contribution of BAT to whole body metabolism (Table 1). For a more exhaustive review of these techniques and tracers we would like to refer to Bauwens et al. [71] and Chondronikola et al. [72].

In Fig. 2, we provide a visual overview of these methods.

\subsection{Skin temperature}

Since active BAT releases energy in the form of heat, one way of measuring this energy is by looking at the temperature around the BAT
Table 1

Overview of different measurements of BAT activity.

\begin{tabular}{|c|c|c|}
\hline \multicolumn{2}{|l|}{ Measurement of BAT aspect } & \multirow{3}{*}{$\begin{array}{l}\text { Quantitative analysis } \\
\text { possible? }\end{array}$} \\
\hline Temperature & & \\
\hline Skin temperature & {$[73-77]$} & \\
\hline \multicolumn{3}{|l|}{ Substrate uptake tracers } \\
\hline 18-Fluor 6 deoxyglucose & {$[6-8,35,61,78-80]$} & Yes, glucose uptake rate \\
\hline $\begin{array}{l}\text { 18-Fluor 6-thia- } \\
\text { heptadecanoidic acid }\end{array}$ & {$[80-83]$} & $\begin{array}{l}\text { Yes, fatty acid uptake } \\
\text { rate }\end{array}$ \\
\hline \multicolumn{3}{|l|}{ Adrenergic innervation } \\
\hline $\begin{array}{l}\text { 123-Iodine meta-iodo- } \\
\text { benzylguanidine }\end{array}$ & [84-87] & $\begin{array}{l}\text { No quantitative analysis, } \\
\text { sympathic innervation }\end{array}$ \\
\hline $\begin{array}{l}\text { 18-Fluor-L- } \\
\quad \text { dihydroxyphenylalanine }\end{array}$ & [88] & $\begin{array}{l}\text { No quantitative analysis, } \\
\text { sympathic innervation }\end{array}$ \\
\hline \multicolumn{3}{|l|}{ Oxidative metabolism tracers } \\
\hline Acetate & {$[80,82]$} & $\begin{array}{l}\text { No quantitative analysis, } \\
\text { oxidative metabolism }\end{array}$ \\
\hline 15-Water & {$[89,90]$} & Yes, blood perfusion \\
\hline 15-Oxygen & {$[89,91]$} & Yes, oxygen consumption \\
\hline \multicolumn{3}{|l|}{ Additional techniques } \\
\hline CT scan (Hounsfield units) & [81] & $\begin{array}{l}\text { No quantitative analysis, } \\
\text { changes in BAT density }\end{array}$ \\
\hline MRI scan & {$[92,93]$} & $\begin{array}{l}\text { Changes in BAT water/ } \\
\text { fat fractions, potential of } \\
\text { measuring metabolic } \\
\text { processes }\end{array}$ \\
\hline Exosomal miRNA & {$[94,95]$} & $\begin{array}{l}\text { Associated with BAT } \\
\text { activity in healthy } \\
\text { subjects }\end{array}$ \\
\hline
\end{tabular}

depots.

As BAT is active and releases heat, one can expect the temperature around the depot to increase. Measuring the skin temperature via thermometers or wireless sensors has been used before, while using the ${ }^{18} \mathrm{~F}^{-}$FDG PET/CT as benchmark [76]. This study by Boon et al. showed a positive correlation between supraclavicular skin temperature upon cold exposure and BAT volume and activity.

Another option is the use of thermal imaging. Via an infrared thermal camera, it is possible to measure the temperature of a larger part of the skin's surface.

It is a quick and easy technique, without radiation exposure or invasive actions [75]. Several studies showed a significant correlation between BAT activity on ${ }^{18} \mathrm{~F}^{-}$FDG PET/CT and the changes in supraclavicular skin temperature $[73,76,77]$. The changes in the supraclavicular skin temperature are not consistent, which may be because of the different cooling techniques, air-cooled vs. water-cooled respectively affecting the skin temperature differently [73].

The downside is that the increase in skin temperature at the cervical depots is off set by the cold exposure used to stimulate BAT. It is therefore difficult to estimate the amount of heat produced by BAT. Furthermore, the infrared thermal imaging and skin temperature do not measure the heat production in the deeper depots [75]. The amount of subcutaneous fat at the cervical region may also hinder the adequate measurement of the effect of BAT on the skin temperature [96,97].

In conclusion: while this technique is non-invasive and is without radiation exposure, it is an imprecise and indirect measurement. At best it is a qualitative approach.

\subsection{Measuring substrate uptake}

The details behind positron emission tomography are well discussed in technical literature [98,99]. In short, a so-called tracer is injected into the subject, after which the tracer will distribute inside the body. Tracers usually consist of a substrate with an attached radioactive 


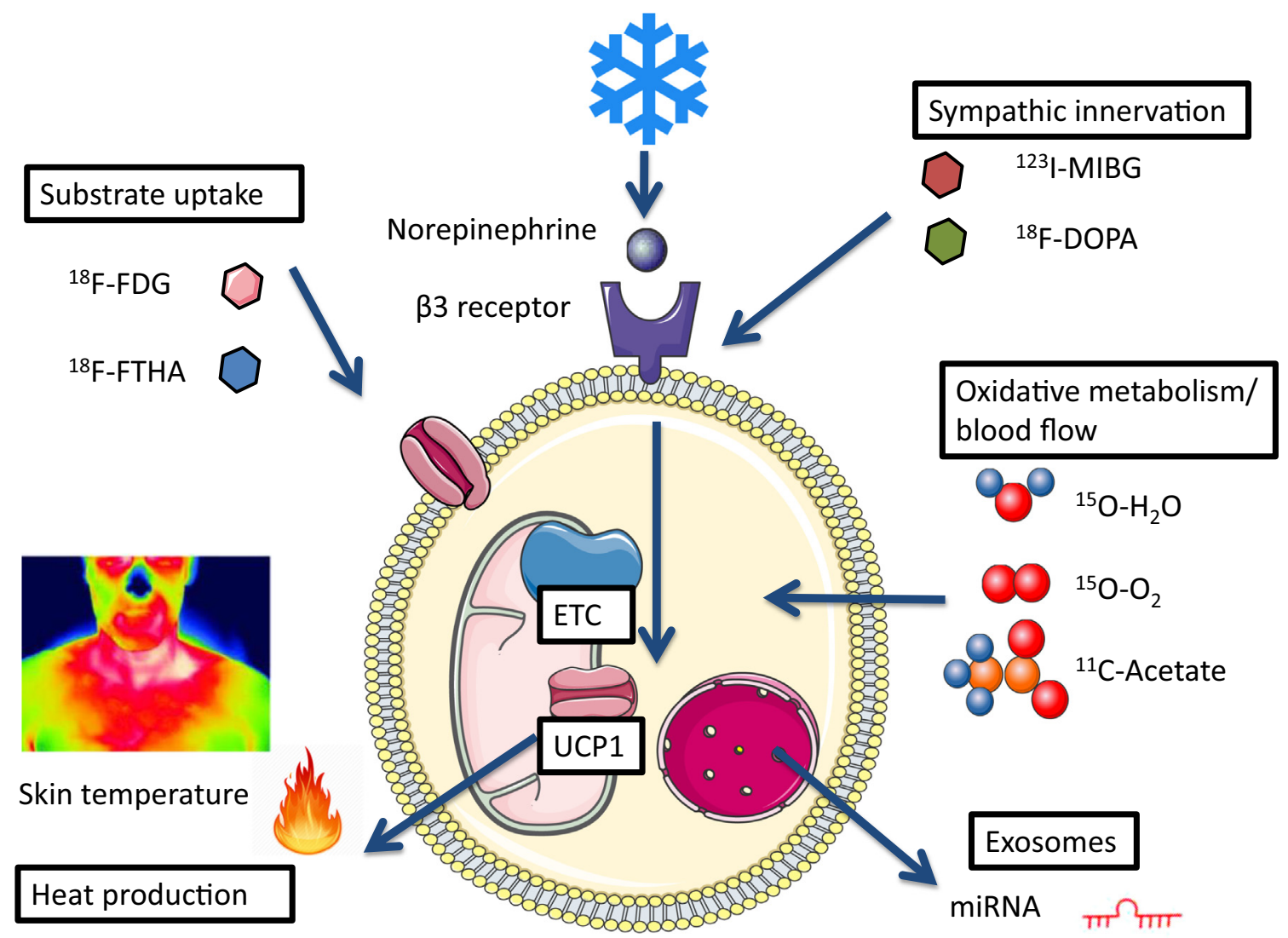

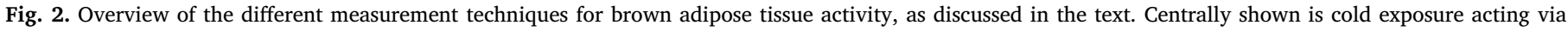

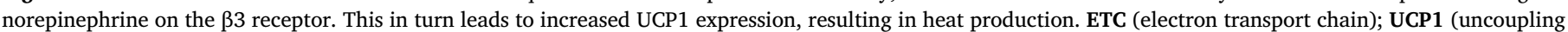

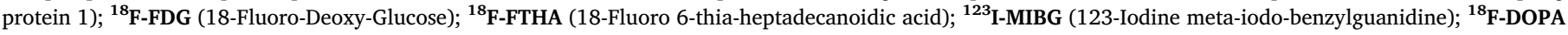
(18-Fluoro-Ldihydroxyphenylalanine).

component. The most well known tracer is ${ }^{18} \mathrm{~F}^{-} \mathrm{FDG}$ (18-fluor deoxyglucose). This consists of glucose, with an attached 18 -fluor atom. Like normal glucose, this ${ }^{18} \mathrm{~F}^{-}$FDG undergoes uptake by glucose transporters $[100,101]$. However, ${ }^{18} \mathrm{~F}^{-}$FDG is then only metabolized to ${ }^{18} \mathrm{~F}$ FDG-6-phosphate, as the next step in the glycolysis does not happen to FDG. This is due to the fact that the enzyme responsible for the next step, glucose-6-phosphate isomerase is unable to convert FDG-6 phosphate. The reverse conversion of ${ }^{18} \mathrm{~F}$-FDG-6-phosphate to ${ }^{18} \mathrm{~F}^{-}$FDG is not possible due to low levels of the necessary enzymes. The ${ }^{18} \mathrm{~F}^{-} \mathrm{FDG}$ remains therefore trapped inside the cell, and is only slowly broken down by other pathways $[100,101]$. As the PET image only shows tissue tracer uptake, another technique is necessary to correlate the positron emission with an anatomical image.

A regular computed tomography, is often performed together with the PET capture. This will provide a detailed anatomical scan, allowing a correlated image. The ${ }^{18} \mathrm{~F}$ is an unstable isotope of the Fluor atom, and will decay into ${ }^{18} \mathrm{O}$, with concomitant release of energy. This released energy will be in the form of positrons, which is measured on a sensor outside the body. The ${ }^{18} \mathrm{~F}^{-}$FDG is mainly trapped and visualized in those tissues of the body that take up glucose, such as the brain, the heart under specific conditions, tumours, and activated BAT.

In the case of brown adipose tissue, the tracer is often administered after and during cold exposure. During the distribution phase, the tracer will localize to the active BAT, if present in the subject. Most tracers are usually used in a static scan, while BAT is a highly dynamic tissue. To measure tissue substrate uptake rate, a dynamic scan method can be used. A dynamic PET/CT, using Patlak curve [102,103] fitting reveals a measure of glucose uptake rate [35].

For comparison between studies the followed procedures of the combined PET/CT (or PET/MR) requires clear descriptions and preferably standardization. In the so-called BARCIST (Brown Adipose Reporting Criteria in Imaging Studies) publication, an expert panel, assembled by the National Institutes of Diabetes and Digestive and Kidney diseases on November 4, 2014, wrote guidelines and suggestions for determining BAT activity in ${ }^{18} \mathrm{~F}^{-}$FDG PET/CT scans [104]. A main guideline states that determining the activity of BAT should be presented using standardized uptake values (SUV). The SUV is calculated as the ratio between the measured radioactivity of the tracer within a region and the dosage of the administered tracer relative to the body weight [104]. This makes comparing the results in repeated measurements or across different subjects possible. However, the subject characteristics, such as BMI (body fat percentage) influence the distribution of the tracer and therefore the SUV in the target tissue [104]. For instance, obese subjects less ${ }^{18} \mathrm{~F}^{-}$FDG uptake is seen in BAT depots, which may be related to a competition with the WAT depots. It may therefore be more applicable to calculate the SUV value as the tracer dosage relative to the lean body mass. Other subject characteristics to take into account are medications, which influence the sympathic nervous system, smoking habits and dietary components such as capsinoids [61]. There is still some uncertainty regarding the fate of the ${ }^{18} \mathrm{~F}^{-}$FDG once taken up and trapped by the BAT cells. It is unknown if it undergoes intracellular metabolism or if it excreted after a certain time period. In diabetic subjects the insulin resistance in these subjects, may lead to less uptake and trapping of ${ }^{18} \mathrm{~F}^{-} \mathrm{FDG}$ in the cells.

Besides the methodological variation, there is also the biological variation of BAT to take in to account. The outdoor temperature and climate also influence the analysis of BAT, as a cold climate or outdoor temperature may stimulate BAT activity and lead to increased BAT volume. Studies regarding cold acclimation and weight loss have shown to increase BAT volume and activity $[13,63,104]$. 
FDG accurately reflects the capacity of tissue to take up glucose and is used as a standard diagnostic tool in cancer patients. However, FDG does not directly reflect the energy expenditure of BAT, where fatty acids (external and internal stored) are the main source of energy [1]. This can have important consequences for the interpretation of results, potentially leading to an underestimation of BAT energy metabolism. Indeed, use of different tracers show that depending on the type of tracer the interpretation of the results (for instance the contribution of BAT to whole body energy expenditure) is different [89,91].

Beyond FDG several alternative tracers - such as $99 \mathrm{mTc}$-sestamibi, 123Imetaiodobenzylguanidine (MIBG), 18F-fluorodopa, perfusion and oxygen consumption studies but also ${ }^{18} \mathrm{~F}-14(R, S)$-FTHA - have been employed for BAT imaging [71]. Fatty acids metabolism (exemplified by FTHA uptake) may be less hampered by associated disturbances in glucose metabolism than FDG uptake in metabolic syndrome. Still for quantification, the use of FTHA may be difficult, because internal brown adipocyte fat stores are also used as fuel during BAT activation.

Besides anatomical information the CT scan can also be used to register BAT activity. CT measures the density of the tissues, which is in the first place used to discriminate between BAT and WAT. However during BAT activation, internal fat stores may be used which affects the density of the BAT. If the density is measured before and after an intervention (for instance cooling), the decrease in density can be used to estimate the lipids combusted by the active BAT [81].

Alternatively, magnetic resonance (MR) scan can be used to make an anatomical scan, instead of a CT scan. This technique allows for highly detailed anatomical information, without the extra radiation exposure a CT scan requires. PET/MRI systems become more widely available. Moreover MRI (Dixon technique) can be used to determine the changes of the fat fraction in tissues that may reflect metabolic activity. Next to monitoring the fat fraction by Dixon MRI, the use of ${ }^{1} \mathrm{H}$ Magnetic Resonance Spectroscopy ( ${ }^{1} \mathrm{H}-\mathrm{MRS}$ ) can be used to follow metabolic changes in activated BAT (for instance NAD + precursor nicotinamide riboside) [93]. Future studies are needed to reveal the applicability.

\subsection{Adrenergic innervation}

Another option is to measure the adrenergic innervation using 123-I meta-iodo-benzyl guanidine $\left({ }^{123} \mathrm{I}-\mathrm{MIBG}\right)$ as tracer. This tracer binds to the adrenergic receptors present on cells, and could thus be used to determine the amount of adrenergic stimulation in BAT. This tracer has been used in diagnosing pheochromocytomas and other tumours of adrenergic origin [86,87]. One study combined ${ }^{18}$ F-FDG-PET/CT with MIBG-SPECT, which showed that both tracers show uptake in the same cervical regions [84], which would then be determined as BAT tissue. Another option is to use 18-Fluor-L-dihydroxyphenylalanine $\left({ }^{18} \mathrm{~F}\right.$ DOPA) as a tracer. This tracer is used in the same capacity as ${ }^{123} \mathrm{I}-\mathrm{MIBG}$, and only a case report describes the use of ${ }^{18} \mathrm{~F}$-DOPA in measuring BAT tissue [88]. Although capable of measuring the sympathic innervation of BAT tissue, for the quantification of the contribution of BAT to whole body metabolism these tracers are not useful.

\subsection{Oxidative metabolism tracers}

The amount of blood flow to BAT can be measured using ${ }^{15} \mathrm{O}$ labelled water $\left({ }^{15} \mathrm{O}-\mathrm{H}_{2} \mathrm{O}\right)$, as well as the oxygen consumption via an oxygen-tracer $\left({ }^{15} \mathrm{O}-\mathrm{O}_{2}\right)$. Only a few studies used these techniques and found that subjects with FDG uptake in the cervical region did have increased blood flow and oxygen consumption [89,90]. However the estimated contribution of BAT to the total energy expenditure is small about $5 \%$ of the total energy expenditure [89].

The major issue is that ${ }^{15} \mathrm{O}$ has an extremely short half-life of about $2 \mathrm{~min}$ [92]. This in combination with the rapidly diffusing isotope and the limited field of view that can be studied with this technique may lead to an underestimation of the BAT activity. The currently available studies also show the need for well attuned cooling procedures and the PET/CT procedure [89,91].

Another option to measure BAT oxidative metabolism is to use 11Carbon Acetate $\left({ }^{11} \mathrm{C}\right.$-Acetate) during dynamic scanning. This tracer is labelled with the 11-C isotope, and undergoes uptake in active tissues. Studies using ${ }^{11} \mathrm{C}$-Acetate have shown a significant oxygen metabolism of human BAT, $[80,82]$. The use of these tracers might actually give the most direct measurement of BAT activity, as they measure the oxidative capacity of BAT.

The short half-life of tracers such as ${ }^{15} \mathrm{O}-\mathrm{O}_{2}$, are issues that would need to be resolved, before they could be used to accurately quantify BAT energy consumption.

\subsection{Exosomal miRNA}

As published by Chen et al. in 2016 and $\mathrm{Ng}$ et al. in 2017, several micro RNA sequences (miRNA's) have been found in association with BAT activity $[94,95]$. Chen et al. analysed serum from both murine brown adipocytes as well as from cultured human brown adipocytes. They found several miRNA's to be expressed differently. One of these miRNA's, miRNA-92 inversely correlated with BAT activity in young healthy subjects, as measured via PET/CT [94]. Ng et al. describe another miRNA, miRNA 32, to be involved in the response of adipocytes to cold stress. After cold stress increased levels of miRNA-32 were associated with browning of white adipocytes, and increased levels of browning markers such as PGC1 $\alpha$ and increased expression of UCP1 [95].

Further evaluation of the use of miRNA's is needed, but the results are promising. The great advantage of this method would be in measuring BAT activity via blood sampling, and would possibly render the use of nuclear imaging and the radiation exposure superfluous.

\section{Contribution of BAT to total body energy expenditure}

In a normal human, the total body energy expenditure (TEE) can be divided in to different components: 1) energy expenditure during sleep (sleeping metabolic rate, SMR), 2) resting energy expenditure during arousal (Basic metabolic rate, BMR), 3) diet-induced energy expenditure (DEE) and the energy expenditure during activity (AEE) $[105,106]$. Diet-induced thermogenesis (DIT) can be divided into an obligatory and a facultative component [107]. The obligatory component is the energy expended to consume, digest and metabolize food, while the facultative component depends on the composition and amount of food consumed [105,108].

The energy expenditure also increases during cold exposure, as the body is stimulated to maintain a stable core temperature. This thermogenesis can in turn be divided in two parts: shivering and non-shivering [109]. Shivering thermogenesis refers to the involuntary muscle contractions, which organisms show upon cold exposure. These contractions occur quickly upon cold exposure and generate heat in an effort to maintain a stable core temperature. Non-shivering occurs mainly in BAT, and is a process requiring adaptation [109].

In order to measure the NST and potentially indirectly BAT activity indirect calorimetry is normally used: the analyses of inhaled and exhaled air. By this means $\mathrm{O}_{2}$ consumption and $\mathrm{CO}_{2}$ production can be determined and the amount of energy expended in time can be calculated [110]. When using this technique during both resting and cold exposure, the increase in energy expenditure upon cold exposure, the NST can be calculated. It appears in many studies that NST strongly correlates with BAT activity measured via ${ }^{18}$ F-FDG PET/CT [7,35].

However the contribution of activated BAT to whole body energy expenditure is still not established. In animals, especially rodents, the role of BAT is more clear-cut than in humans. The studies using tracers ${ }^{15} \mathrm{O}-\mathrm{O}_{2}$, which actually measure oxygen usage have all shown that the overall contribution of BAT to total energy expenditure comes down to about $1-5 \%$ of resting metabolic rate (RMR) [89,91]. Though very 
interesting experiments, these measurements are hampered by the short half life of the isotopes of $2 \mathrm{~min}$, the rapidly diffusing isotope and the use of a limited field of view (only a small part of the body is actually scanned). The authors therefore conclude that the activity of BAT may be underestimated. Their results are lower than based on an earlier estimation of BAT contribution using BAT metabolic rate from rodents and allometric comparison, as done by Van Marken Lichtenbelt and Schrauwen [107]. Their calculation revealed an estimation of $5 \%$ of RMR. The data of the study of van der Lans et al. [35], who performed a dynamic ${ }^{18} \mathrm{~F}$-FDG PET/CT scan, show that glucose uptake rate varied substantially between subjects, from almost zero to more than $25 \mu \mathrm{mol} /$ g BAT. When using these numbers maximal BAT activity comes up to $16 \%$ of RMR and almost $90 \%$ of NST.

Although the current contribution of BAT is still a matter of dispute in humans, the potential of BAT can be significant. All current studies to increase BAT focus on a short period of exposure to cold (cold acclimation) or pharmacological stimulation.

Cold acclimation, even as short as 10 days has shown to increase BAT activity and volume [35]. As seen in different acclimation studies, the energy expenditure of BAT increases after acclimation, as well as the oxidative capacity $[35,80,111]$. A more recent study by Leitner et al. showed that FDG-uptake upon cold exposure also occurs outside of the classical BAT depots [10]. They also show the ${ }^{18}$ F-FDG uptake in a patient with a paraganglioma with a long exposure to high levels of adrenergic hormones. This shows ${ }^{18}$ F-FDG uptake in the perirenal and subcostal WAT depots. This would mean that potentially these regions could be stimulated to develop BAT-like properties. Estimated by Leitner et al. a maximum of $115.5 \mathrm{kcal} / \mathrm{d}$ could be produced by the entire BAT volume [10].

This estimation would lead to the conclusion that most studies thus far, have only shown an under appreciation of brown adipose tissue. A stronger or longer exposure to cold or pharmacological stimulants could lead to a much larger contribution of BAT to energy expenditure. The effect on metabolic health in that regard could be significant. Earlier studies have shown some effects on lipid and glucose metabolism, $[78,81]$ but a much more profound effect on metabolic health would be a welcome sight.

In order to maximize the effect of BAT, more exposure to cold would be desirable. However most studies have used a temperature of around 14-16 degrees Celsius, which is often not appreciated by subjects. A prolonged exposure to a less cold environment, may be a potential solution. New research should not only focus on finding new stimulants for BAT, but also on increasing the potential of BAT in humans.

Although increasing energy expenditure can influence the energy balance, potential compensation can occur by increased food intake. This could lead to attenuation of beneficial effects of increased energy expenditure on health and metabolism. There are indications that not all of the increase in energy expenditure is compensated [112].

Another issue is the potential negative consequence of a prolonged increase in energy expenditure in obese subjects. Several observational studies showed that obese subjects with heart failure might have a better prognosis then lean subjects with heart failure [113,114]. This so-called obesity paradox indicates that increasing energy expenditure to combat obesity should be closely observed for long-term cardiovascular side effects. In this case, the goal should be weight maintenance and not decrease of body weight.

To conclude, brown adipose tissue remains an interesting and possibly underestimated target in metabolic health. It still needs further exploration to what extent BAT activation can become a new treatment for obesity and it's complications.

\section{Transparency document}

The Transparency document associated with this article can be found, in online version.

\section{Acknowledgments}

We acknowledge the support of the Dutch Heart Foundation (CVON2014-02 ENERGISE) and the European Foundation for the study of Diabetes (EFSD).

\section{References}

[1] B. Cannon, J. Nedergaard, Brown adipose tissue: function and physiological significance, Physiol. Rev. 84 (1) (2004) 277-359.

[2] J. Himms-Hagen, Brown adipose tissue metabolism and thermogenesis, Annu. Rev. Nutr. 5 (1985) 69-94.

[3] J.M. Heaton, The distribution of brown adipose tissue in the human, J. Anat. 112 (Pt 1) (1972) 35-39.

[4] P. Huttunen, J. Hirvonen, V. Kinnula, The occurrence of brown adipose tissue in outdoor workers, Eur. J. Appl. Physiol. Occup. Physiol. 46 (4) (1981) 339-345.

[5] J. Nedergaard, T. Bengtsson, B. Cannon, Unexpected evidence for active brown adipose tissue in adult humans, Am. J. Physiol. Endocrinol. Metab. 293 (2) (2007) E444-E452.

[6] A.M. Cypess, S. Lehman, G. Williams, I. Tal, D. Rodman, A.B. Goldfine, et al., Identification and importance of brown adipose tissue in adult humans, N. Engl. J. Med. 360 (15) (2009) 1509-1517.

[7] W.D. van Marken Lichtenbelt, J.W. Vanhommerig, N.M. Smulders, J.M. Drossaerts, G.J. Kemerink, N.D. Bouvy, et al., Cold-activated brown adipose tissue in healthy men, N. Engl. J. Med. 360 (15) (2009) 1500-1508.

[8] K.A. Virtanen, M.E. Lidell, J. Orava, M. Heglind, R. Westergren, T. Niemi, et al. Functional brown adipose tissue in healthy adults, N. Engl. J. Med. 360 (15) (2009) 1518-1525.

[9] R.E. Smith, Thermoregulatory and adaptive behavior of brown adipose tissue, Science 146 (3652) (1964) 1686-1689.

[10] B.P. Leitner, S. Huang, R.J. Brychta, C.J. Duckworth, A.S. Baskin, S. McGehee, et al., Mapping of human brown adipose tissue in lean and obese young men, Proc Natl. Acad. Sci. U. S. A. 114 (32) (2017) 8649-8654.

[11] B.B. Lowell, B.M. Spiegelman, Towards a molecular understanding of adaptive thermogenesis, Nature 404 (6778) (2000) 652-660.

[12] S. Amir, Intra-ventromedial hypothalamic injection of glutamate stimulates brown adipose tissue thermogenesis in the rat, Brain Res. 511 (2) (1990) 341-344.

[13] O. Parysow, A.M. Mollerach, V. Jager, S. Racioppi, J. San Roman, V.H. Gerbaudo, Low-dose oral propranolol could reduce brown adipose tissue F-18 FDG uptake in patients undergoing PET scans, Clin. Nucl. Med. 32 (5) (2007) 351-357.

[14] A.C. Bianco, J.E. Silva, Intracellular conversion of thyroxine to triiodothyronine is required for the optimal thermogenic function of brown adipose tissue, J. Clin. Invest. 79 (1) (1987) 295-300.

[15] A.C. Bianco, J.E. Silva, Nuclear 3,5,3'-triiodothyronine (T3) in brown adipose tissue: receptor occupancy and sources of T3 as determined by in vivo techniques, Endocrinology 120 (1) (1987) 55-62.

[16] J.E. Silva, Thyroid hormone control of thermogenesis and energy balance, Thyroid 5 (6) (1995) 481-492.

[17] T.J. Schulz, P. Huang, T.L. Huang, R. Xue, L.E. Mcdougall, K.L. Townsend, et al., Brown-fat paucity due to impaired BMP signalling induces compensatory browning of white fat, Nature 495 (7441) (2013) 379-383.

[18] J.A. Timmons, K. Wennmalm, O. Larsson, T.B. Walden, T. Lassmann, N. Petrovic, et al., Myogenic gene expression signature establishes that brown and white adipocytes originate from distinct cell lineages, Proc. Natl. Acad. Sci. U. S. A. 104 (11) (2007) 4401-4406.

[19] M.J. Barbera, A. Schluter, N. Pedraza, R. Iglesias, F. Villarroya, M. Giralt, Peroxisome proliferator-activated receptor alpha activates transcription of the brown fat uncoupling protein-1 gene. A link between regulation of the thermogenic and lipid oxidation pathways in the brown fat cell, J. Biol. Chem. 276 (2) (2001) 1486-1493.

[20] P. Seale, B. Bjork, W. Yang, S. Kajimura, S. Chin, S. Kuang, et al., PRDM16 controls a brown fat/skeletal muscle switch, Nature 454 (7207) (2008) 961-967.

[21] M.J. Harms, J. Ishibashi, W. Wang, H.W. Lim, S. Goyama, T. Sato, et al., Prdm16 is required for the maintenance of brown adipocyte identity and function in adult mice, Cell Metab. 19 (4) (2014) 593-604.

[22] P. Young, J.R. Arch, M. Ashwell, Brown adipose tissue in the parametrial fat pad of the mouse, FEBS Lett. 167 (1) (1984) 10-14.

[23] N. Petrovic, T.B. Walden, I.G. Shabalina, J.A. Timmons, B. Cannon, J. Nedergaard, Chronic peroxisome proliferator-activated receptor gamma (PPARgamma) activation of epididymally derived white adipocyte cultures reveals a population of thermogenically competent, UCP1-containing adipocytes molecularly distinct from classic brown adipocytes, J. Biol. Chem. 285 (10) (2010) 7153-7164.

[24] J. Wu, P. Bostrom, L.M. Sparks, L. Ye, J.H. Choi, A.H. Giang, et al., Beige adipocytes are a distinct type of thermogenic fat cell in mouse and human, Cell 150 (2) (2012) 366-376.

[25] M. Giralt, F. Villarroya, White, brown, beige/brite: different adipose cells for different functions? Endocrinology 154 (9) (2013) 2992-3000.

[26] C. Guerra, R.A. Koza, H. Yamashita, K. Walsh, L.P. Kozak, Emergence of brown adipocytes in white fat in mice is under genetic control. Effects on body weight and adiposity, J. Clin. Invest. 102 (2) (1998) 412-420.

[27] M. Rosenwald, A. Perdikari, T. Rulicke, C. Wolfrum, Bi-directional interconversion of brite and white adipocytes, Nat. Cell Biol. 15 (6) (2013) 659-667.

[28] M.E. Lidell, M.J. Betz, O. Dahlqvist Leinhard, M. Heglind, L. Elander, M. Slawik, 
et al., Evidence for two types of brown adipose tissue in humans, Nat. Med. 19 (5) (2013) 631-634.

[29] L.Z. Sharp, K. Shinoda, H. Ohno, D.W. Scheel, E. Tomoda, L. Ruiz, et al., Human BAT possesses molecular signatures that resemble beige/brite cells, PLoS One 7 (11) (2012) e49452.

[30] J.Z. Long, K.J. Svensson, L. Tsai, X. Zeng, H.C. Roh, X. Kong, et al., A smooth muscle-like origin for beige adipocytes, Cell Metab. 19 (5) (2014) 810-820.

[31] T. Yoneshiro, S. Aita, M. Matsushita, Y. Okamatsu-Ogura, T. Kameya, Y. Kawai, et al., Age-related decrease in cold-activated brown adipose tissue and accumulation of body fat in healthy humans, Obesity (Silver Spring) 19 (9) (2011) 1755-1760.

[32] G.H. Vijgen, N.D. Bouvy, G.J. Teule, B. Brans, P. Schrauwen, W.D. van Marken Lichtenbelt, Brown adipose tissue in morbidly obese subjects, PLoS One 6 (2) (2011) e17247.

[33] M. Saito, T. Yoneshiro, M. Matsushita, Activation and recruitment of brown adipose tissue by cold exposure and food ingredients in humans, Best Pract. Res. Clin. Endocrinol. Metab. 30 (4) (2016) 537-547.

[34] T. Yoneshiro, S. Aita, M. Matsushita, T. Kayahara, T. Kameya, Y. Kawai, et al., Recruited brown adipose tissue as an antiobesity agent in humans, J. Clin. Invest. 123 (8) (2013) 3404-3408.

[35] A.A. van der Lans, J. Hoeks, B. Brans, G.H. Vijgen, M.G. Visser, M.J. Vosselman, et al., Cold acclimation recruits human brown fat and increases nonshivering thermogenesis, J. Clin. Invest. 123 (8) (2013) 3395-3403.

[36] E.P. Broeders, E.B. Nascimento, B. Havekes, B. Brans, K.H. Roumans, A. Tailleux, et al., The bile acid chenodeoxycholic acid increases human brown adipose tissue activity, Cell Metab. 22 (3) (2015) 418-426.

[37] A.M. Cypess, A.P. White, C. Vernochet, T.J. Schulz, R. Xue, C.A. Sass, et al., Anatomical localization, gene expression profiling and functional characterization of adult human neck brown fat, Nat. Med. 19 (5) (2013) 635-639.

[38] N.Z. Jespersen, T.J. Larsen, L. Peijs, S. Daugaard, P. Homoe, A. Loft, et al., A classical brown adipose tissue mRNA signature partly overlaps with brite in the supraclavicular region of adult humans, Cell Metab. 17 (5) (2013) 798-805.

[39] J.M. de Jong, O. Larsson, B. Cannon, J. Nedergaard, A stringent validation of mouse adipose tissue identity markers, Am. J. Physiol. Endocrinol. Metab. 308 (12) (2015) E1085-E1105.

[40] M. Harms, P. Seale, Brown and beige fat: development, function and therapeutic potential, Nat. Med. 19 (10) (2013) 1252-1263.

[41] W. Wang, P. Seale, Control of brown and beige fat development, Nat. Rev. Mol. Cell Biol. 17 (11) (2016) 691-702.

[42] H. Koepsell, K. Lips, C. Volk, Polyspecific organic cation transporters: structure, function, physiological roles, and biopharmaceutical implications, Pharm. Res. 24 (7) (2007) 1227-1251.

[43] P. Breining, S.B. Pedersen, A. Pikelis, L. Rolighed, E.I. Sundelin, N. Jessen, et al., High expression of organic cation transporter 3 in human BAT-like adipocytes. Implications for extraneuronal norepinephrine uptake, Mol. Cell. Endocrinol. 443 (2017) 15-22.

[44] M. Boll, M. Foltz, I. Rubio-Aliaga, H. Daniel, A cluster of proton/amino acid transporter genes in the human and mouse genomes, Genomics 82 (1) (2003) 47-56.

[45] J.R. Bermingham Jr., J. Pennington, Organization and expression of the SLC36 cluster of amino acid transporter genes, Mamm. Genome 15 (2) (2004) 114-125.

[46] S. Ussar, K.Y. Lee, S.N. Dankel, J. Boucher, M.F. Haering, A. Kleinridders, et al., ASC-1, PAT2, and P2RX5 are cell surface markers for white, beige, and brown adipocytes, Sci. Transl. Med. 6 (247) (2014) $247 \mathrm{ra} 103$.

[47] D. Rockstroh, K. Landgraf, I.V. Wagner, J. Gesing, R. Tauscher, N. Lakowa, et al., Direct evidence of brown adipocytes in different fat depots in children, PLoS One 10 (2) (2015) e0117841.

[48] K.T. Le, M. Paquet, D. Nouel, K. Babinski, P. Seguela, Primary structure and expression of a naturally truncated human P2X ATP receptor subunit from brain and immune system, FEBS Lett. 418 (1-2) (1997) 195-199.

[49] W.R. Haines, G.E. Torres, M.M. Voigt, T.M. Egan, Properties of the novel ATPgated ionotropic receptor composed of the P2X(1) and P2X(5) isoforms, Mol. Pharmacol. 56 (4) (1999) 720-727.

[50] S. Seibold, C. Rudroff, M. Weber, J. Galle, C. Wanner, M. Marx, Identification of a new tumor suppressor gene located at chromosome 8p21.3-22, FASEB J. 17 (9) (2003) 1180-1182

[51] K. Shinoda, I.H. Luijten, Y. Hasegawa, H. Hong, S.B. Sonne, M. Kim, et al., Genetic and functional characterization of clonally derived adult human brown adipocytes, Nat. Med. 21 (4) (2015) 389-394.

[52] F. Jing, M. Mogi, L.J. Min, K. Ohshima, H. Nakaoka, K. Tsukuda, et al., Effect of angiotensin II type 2 receptor-interacting protein on adipose tissue function via modulation of macrophage polarization, PLoS One 8 (4) (2013) e60067.

[53] F. Duprat, F. Lesage, M. Fink, R. Reyes, C. Heurteaux, M. Lazdunski, TASK, a human background $\mathrm{K}+$ channel to sense external $\mathrm{pH}$ variations near physiological pH, EMBO J. 16 (17) (1997) 5464-5471.

[54] P.A. Svensson, M. Jernas, K. Sjoholm, J.M. Hoffmann, B.E. Nilsson, M. Hansson, et al., Gene expression in human brown adipose tissue, Int. J. Mol. Med. 27 (2) (2011) 227-232.

[55] E.B. Nascimento, L.M. Sparks, A. Divoux, M.W. Van Gisbergen, E.P. Broeders, J.A. Jorgensen, et al., Genetic markers of brown adipose tissue identity and in vitro brown adipose tissue activity in humans, Obesity (Silver Spring) 26 (1) (2018) 135-140

[56] Y. Chen, X. Zeng, X. Huang, S. Serag, C.J. Woolf, B.M. Spiegelman, Crosstalk between KCNK3-mediated ion current and adrenergic signaling regulates adipose thermogenesis and obesity, Cell 171 (4) (2017) 836-848.

[57] T. Gnad, S. Scheibler, I. von Kugelgen, C. Scheele, A. Kilic, A. Glode, et al.,
Adenosine activates brown adipose tissue and recruits beige adipocytes via A2A receptors, Nature 516 (7531) (2014) 395-399.

[58] J.B. Sousa, C. Diniz, The adenosinergic system as a therapeutic target in the vasculature: new ligands and challenges, Molecules 22 (5) (2017).

[59] M.J. Vosselman, A.A. van der Lans, B. Brans, R. Wierts, M.A. van Baak, P. Schrauwen, et al., Systemic beta-adrenergic stimulation of thermogenesis is not accompanied by brown adipose tissue activity in humans, Diabetes 61 (12) (2012) 3106-3113.

[60] A.M. Cypess, Y.C. Chen, C. Sze, K. Wang, J. English, O. Chan, et al., Cold but not sympathomimetics activates human brown adipose tissue in vivo, Proc. Natl. Acad. Sci. U. S. A. 109 (25) (2012) 10001-10005.

[61] A.M. Cypess, L.S. Weiner, C. Roberts-Toler, E. Franquet Elia, S.H. Kessler, P.A. Kahn, et al., Activation of human brown adipose tissue by a beta3-adrenergic receptor agonist, Cell Metab. 21 (1) (2015) 33-38.

[62] L.P. Kozak, Brown fat and the myth of diet-induced thermogenesis, Cell Metab. 11 (4) (2010) 263-267.

[63] M.J. Vosselman, B. Brans, A.A. van der Lans, R. Wierts, M.A. van Baak, F.M. Mottaghy, et al., Brown adipose tissue activity after a high-calorie meal in humans, Am. J. Clin. Nutr. 98 (1) (2013) 57-64.

[64] M. Saito, Brown adipose tissue as a therapeutic target for human obesity, Obes Res Clin Pract. 7 (6) (2013) e432-e438.

[65] A.G. Dulloo, J. Seydoux, L. Girardier, P. Chantre, J. Vandermander, Green tea and thermogenesis: interactions between catechin-polyphenols, caffeine and sympathetic activity, Int. J. Obes. Relat. Metab. Disord. 24 (2) (2000) 252-258.

[66] M. Westerterp-Plantenga, K. Diepvens, A.M. Joosen, S. Berube-Parent, A. Tremblay, Metabolic effects of spices, teas, and caffeine, Physiol. Behav. 89 (1) (2006) 85-91.

[67] T. Yoneshiro, S. Aita, Y. Kawai, T. Iwanaga, M. Saito, Nonpungent capsaicin analogs (capsinoids) increase energy expenditure through the activation of brown adipose tissue in humans, Am. J. Clin. Nutr. 95 (4) (2012) 845-850.

[68] S. Li, Y. Li, L. Xiang, J. Dong, M. Liu, G. Xiang, Sildenafil induces browning of subcutaneous white adipose tissue in overweight adults, Metabolism 78 (2017) $106-117$.

[69] L.S. Hoffmann, J. Etzrodt, L. Willkomm, A. Sanyal, L. Scheja, A.W. Fischer, et al., Stimulation of soluble guanylyl cyclase protects against obesity by recruiting brown adipose tissue, Nat. Commun. 6 (2015) 7235.

[70] A. Pfeifer, A. Kilic, L.S. Hoffmann, Regulation of metabolism by cGMP, Pharmacol. Ther. 140 (1) (2013) 81-91.

[71] M. Bauwens, R. Wierts, B. van Royen, J. Bucerius, W. Backes, F. Mottaghy, et al., Molecular imaging of brown adipose tissue in health and disease, Eur. J. Nucl. Med. Mol. Imaging 41 (4) (2014) 776-791.

[72] M. Chondronikola, S.C. Beeman, R.L. Wahl, Non-invasive methods for the assessment of brown adipose tissue in humans, J. Physiol. 596 (3) (2018) 363-378.

[73] A.A. van der Lans, M.J. Vosselman, M.J. Hanssen, B. Brans, W.D. van Marken Lichtenbelt, Supraclavicular skin temperature and BAT activity in lean healthy adults, J. Physiol. Sci. 66 (1) (2016) 77-83.

[74] D.J. Mccafferty, The value of infrared thermography for research on mammals: previous applications and future directions, Mammal Rev. 37 (3) (2007) 207-223.

[75] C. Jang, S. Jalapu, M. Thuzar, P.W. Law, S. Jeavons, J.L. Barclay, et al., Infrared thermography in the detection of brown adipose tissue in humans, Phys. Rep. 2 (11) (2014).

[76] M.R. Boon, L.E. Bakker, R.A. van der Linden, L. Pereira Arias-Bouda, F. Smit, H.J. Verberne, et al., Supraclavicular skin temperature as a measure of 18F-FDG uptake by BAT in human subjects, PLoS One 9 (6) (2014) e98822.

[77] M.E. Symonds, K. Henderson, L. Elvidge, C. Bosman, D. Sharkey, A.C. Perkins, et al., Thermal imaging to assess age-related changes of skin temperature within the supraclavicular region co-locating with brown adipose tissue in healthy children, J. Pediatr. 161 (5) (2012) 892-898.

[78] M.J. Hanssen, J. Hoeks, B. Brans, A.A. van der Lans, G. Schaart, J.J. van den Driessche, et al., Short-term cold acclimation improves insulin sensitivity in patients with type 2 diabetes mellitus, Nat. Med. 21 (8) (2015) 863-865.

[79] T.S. Hong, A. Shammas, M. Charron, K.A. Zukotynski, L.A. Drubach, R. Lim, Brown adipose tissue 18F-FDG uptake in pediatric PET/CT imaging, Pediatr. Radiol. 41 (6) (2011) 759-768.

[80] V. Ouellet, S.M. Labbe, D.P. Blondin, S. Phoenix, B. Guerin, F. Haman, et al., Brown adipose tissue oxidative metabolism contributes to energy expenditure during acute cold exposure in humans, J. Clin. Invest. 122 (2) (2012) 545-552.

[81] A. Bartelt, O.T. Bruns, R. Reimer, H. Hohenberg, H. Ittrich, K. Peldschus, et al., Brown adipose tissue activity controls triglyceride clearance, Nat. Med. 17 (2) (2011) 200-205.

[82] D.P. Blondin, S.M. Labbe, H.C. Tingelstad, C. Noll, M. Kunach, S. Phoenix, et al., Increased brown adipose tissue oxidative capacity in cold-acclimated humans, J. Clin. Endocrinol. Metab. 99 (3) (2014) E438-E446.

[83] S.M. Labbe, A. Caron, I. Bakan, M. Laplante, A.C. Carpentier, R. Lecomte, et al., In vivo measurement of energy substrate contribution to cold-induced brown adipose tissue thermogenesis, FASEB J. 29 (5) (2015) 2046-2058.

[84] W.M. Admiraal, F. Holleman, L. Bahler, M.R. Soeters, J.B. Hoekstra, H.J. Verberne, Combining 123I-metaiodobenzylguanidine SPECT/CT and 18F-FDG PET/CT for the assessment of brown adipose tissue activity in humans during cold exposure, J. Nucl. Med. 54 (2) (2013) 208-212.

[85] W.M. Admiraal, H.J. Verberne, F.A. Karamat, M.R. Soeters, J.B. Hoekstra, F. Holleman, Cold-induced activity of brown adipose tissue in young lean men of south-Asian and European origin, Diabetologia 56 (10) (2013) 2231-2237.

[86] M.J. Gelfand, 123I-MIBG uptake in the neck and shoulders of a neuroblastoma patient: damage to sympathetic innervation blocks uptake in brown adipose tissue, Pediatr. Radiol. 34 (7) (2004) 577-579. 
[87] C. Okuyama, N. Sakane, T. Yoshida, K. Shima, H. Kurosawa, K. Kumamoto, et al., (123)I- or (125)I-metaiodobenzylguanidine visualization of brown adipose tissue, J. Nucl. Med. 43 (9) (2002) 1234-1240.

[88] E. Sondergaard, L.C. Gormsen, M.H. Christensen, S.B. Pedersen, P. Christiansen, S. Nielsen, et al., Chronic adrenergic stimulation induces brown adipose tissue differentiation in visceral adipose tissue, Diabet. Med. 32 (2) (2015) e4-e8.

[89] O. Muzik, T.J. Mangner, J.G. Granneman, Assessment of oxidative metabolism in brown fat using PET imaging, Front. Endocrinol. 3 (2012) 15.

[90] J. Orava, P. Nuutila, M.E. Lidell, V. Oikonen, T. Noponen, T. Viljanen, et al., Different metabolic responses of human brown adipose tissue to activation by cold and insulin, Cell Metab. 14 (2) (2011) 272-279.

[91] M. Ud, J. Raiko, T. Saari, N. Kudomi, T. Tolvanen, V. Oikonen, et al., Human brown adipose tissue [(15)O]O2 PET imaging in the presence and absence of cold stimulus, Eur. J. Nucl. Med. Mol. Imaging 43 (10) (2016) 1878-1886.

[92] M. Borga, K.A. Virtanen, T. Romu, O.D. Leinhard, A. Persson, P. Nuutila, et al., Brown adipose tissue in humans: detection and functional analysis using PET (positron emission tomography), MRI (magnetic resonance imaging), and DECT (dual energy computed tomography), Methods Enzymol. 537 (2014) 141-159.

[93] C. Canto, R.H. Houtkooper, E. Pirinen, D.Y. Youn, M.H. Oosterveer, Y. Cen, et al., The $N A D(+)$ precursor nicotinamide riboside enhances oxidative metabolism and protects against high-fat diet-induced obesity, Cell Metab. 15 (6) (2012) 838-847.

[94] Y. Chen, J.J. Buyel, M.J. Hanssen, F. Siegel, R. Pan, J. Naumann, et al., Exosomal microRNA miR-92a concentration in serum reflects human brown fat activity, Nat. Commun. 7 (2016) 11420.

[95] R. Ng, N.A. Hussain, Q. Zhang, C. Chang, H. Li, Y. Fu, et al., miRNA-32 drives brown fat thermogenesis and trans-activates subcutaneous white fat browning in mice, Cell Rep. 19 (6) (2017) 1229-1246.

[96] T. Haq, J.D. Crane, S. Kanji, E. Gunn, M.A. Tarnopolsky, H.C. Gerstein, et al., Optimizing the methodology for measuring supraclavicular skin temperature using infrared thermography; implications for measuring brown adipose tissue activity in humans, Sci. Rep. 7 (1) (2017) 11934.

[97] S. Gatidis, H. Schmidt, C.A. Pfannenberg, K. Nikolaou, F. Schick, N.F. Schwenzer, Is it possible to detect activated brown adipose tissue in humans using single-timepoint infrared thermography under thermoneutral conditions? Impact of BMI and subcutaneous adipose tissue thickness, PLoS One 11 (3) (2016) e0151152.

[98] G. Muehllehner, J.S. Karp, Positron emission tomography, Phys. Med. Biol. 51 (13) (2006) R117-R137.

[99] M.E. Raichle, Positron emission tomography, Annu. Rev. Neurosci. 6 (1983) 249-267.

[100] B.M. Gallagher, J.S. Fowler, N.I. Gutterson, R.R. Macgregor, C.N. Wan, A.P. Wolf, Metabolic trapping as a principle of oradiopharmaceutical design: some factors resposible for the biodistribution of [18F] 2-deoxy-2-fluoro-D-glucose, J. Nucl.
Med. 19 (10) (1978) 1154-1161.

[101] P. Rigo, P. Paulus, B.J. Kaschten, R. Hustinx, T. Bury, G. Jerusalem, et al., Oncological applications of positron emission tomography with fluorine-18 fluorodeoxyglucose, Eur. J. Nucl. Med. 23 (12) (1996) 1641-1674.

[102] M.M. Graham, L.M. Peterson, R.M. Hayward, Comparison of simplified quantitative analyses of FDG uptake, Nucl. Med. Biol. 27 (7) (2000) 647-655.

[103] C.S. Patlak, R.G. Blasberg, Graphical evaluation of blood-to-brain transfer constants from multiple-time uptake data. Generalizations, J. Cereb. Blood Flow Metab. 5 (4) (1985) 584-590.

[104] K.Y. Chen, A.M. Cypess, M.R. Laughlin, C.R. Haft, H.H. Hu, M.A. Bredella, et al., Brown adipose reporting criteria in imaging STudies (BARCIST 1.0): recommendations for standardized FDG-PET/CT experiments in humans, Cell Metab. 24 (2) (2016) 210-222.

[105] K.R. Westerterp, Physical activity and physical activity induced energy expenditure in humans: measurement, determinants, and effects, Front. Physiol. 4 (2013) 90.

[106] K.R. Westerterp, W.P. Verboeket-Van De Venne, C.V. Bouten, C. de Graaf, K.H. van het Hof, J.A. Weststrate, Energy expenditure and physical activity in subjects consuming full-or reduced-fat products as part of their normal diet, Br. J. Nutr. 76 (6) (1996) 785-795.

[107] W.D. van Marken Lichtenbelt, P. Schrauwen, Implications of nonshivering thermogenesis for energy balance regulation in humans, Am. J. Phys. Regul. Integr. Comp. Phys. 301 (2) (2011) R285-R296.

[108] K.R. Westerterp, Diet induced thermogenesis, Nutr. Metab. (Lond.) 1 (1) (2004) 5.

[109] B. Cannon, J. Nedergaard, Nonshivering thermogenesis and its adequate measurement in metabolic studies, J. Exp. Biol. 214 (Pt 2) (2011) 242-253.

[110] E. Ferrannini, The theoretical bases of indirect calorimetry: a review, Metabolism 37 (3) (1988) 287-301.

[111] M.J. Hanssen, A.A. van der Lans, B. Brans, J. Hoeks, K.M. Jardon, G. Schaart, et al., Short-term cold acclimation recruits brown adipose tissue in obese humans, Diabetes 65 (5) (2016) 1179-1189.

[112] B. Cannon, J. Nedergaard, Thermogenesis challenges the adipostat hypothesis for body-weight control, Proc. Nutr. Soc. 68 (4) (2009) 401-407.

[113] G.C. Fonarow, P. Srikanthan, M.R. Costanzo, G.B. Cintron, M. Lopatin, A.S.A. Committee, et al., An obesity paradox in acute heart failure: analysis of body mass index and inhospital mortality for 108,927 patients in the Acute Decompensated Heart Failure National Registry, Am. Heart J. 153 (1) (2007) $74-81$.

[114] C.J. Lavie, R.V. Milani, S.M. Artham, D.A. Patel, H.O. Ventura, The obesity paradox, weight loss, and coronary disease, Am. J. Med. 122 (12) (2009) $1106-1114$ 